\title{
A Comunicação na Esfera Pública: o que se publicou entre 1998 e 2008 no Congresso Brasileiro de Ciências da Comunicação do Intercom
}

\section{The Communication in the Public Scope: what has been published between 1998 and 2008 in the Brazilian Congress of Intercom Science Communication}

Artigo

Original

\author{
Francine Lucatelli ${ }^{1}$ \\ Marcos Antonio Ribeiro Andrade ${ }^{2}$
}

Original

Paper

\section{Palavras-chave:}

Bibliometria

Comunicação

Esfera Pública

Intercom

\section{Resumo:}

Esta pesquisa foi norteada pelo interesse em analisar e quantificar os artigos publicados no Intercom que remetem à comunicação na esfera pública. Para a realização desta, efetuou-se uma pesquisa no site da Sociedade Brasileira de Estudos Interdisciplinares da Comunicação, e verificou-se o que foi publicado entre os anos de 1998 e 2008. Posteriormente, utilizou-se algumas expressões como: Comunicação Governamental, Comunicação Pública, Comunicação Política, Marketing Político e Propaganda Política para delimitar uma amostra de pesquisa. Num segundo momento efetuouse o fichamento desses artigos e a posteriori, utilizando-se da pesquisa bibliométrica, buscou-se quantificar as informações coletadas para identificar quanto se publicou na área, quais autores mais serviram de referência bibliográfica e sobre quais expressões os artigos pesquisados mais discorreram. Também foi possível evidenciar o pouco interesse pelo tema por parte dos profissionais formados em comunicação, o que acaba por abrir espaço para que profissionais de outras áreas se dediquem a estudar a comunicação no campo da esfera pública.

\section{Abstract}

This research was guided by the interest in analyzing and quantifying the papers published in the Intercom referring to the communication in the public scope. To achieve this, we performed a search on the site of the Brazilian Society for Interdisciplinary Studies of Communication, and found out what was published between the years 1998 and 2008. Later we used some expressions such as: Government Communication, Public Communication, Political Communication, Political Marketing and Political Advertising to define a sample search. In a second step we performed the registration process of these articles, and, a posteriori, using the bibliometric survey, we attempted to quantify the collected information to indentify how much was published in the area, which authors could serve more often as bibliographical reference and which expressions the research articles approached more often. It was also possible to highlight the little interest of the professionals graduated in communication into this theme, and tends to open space for professionals coming from other areas to dedicate and study communication in the public scope.
}

Key words:

Bibliometrics

Comunication

Public Scope

Intercom
Recebido em 04/2011

Aprovado em 12/2011

\footnotetext{
${ }^{1}$ MBA em Marketing Estratégico, Bacharel em Comunicação Social - Relações Públicas - Universidade do Vale do Itajaí

${ }^{2}$ Bacharel e Mestre em Administração, Especialista em Gestão Organizacional - UniFOA
} 


\section{Introdução}

A atividade de Relações Públicas remonta aos primórdios da humanidade, pois a reunião de seres humanos, a prática do comércio e o desenvolvimento da política administrativa foram ações que favoreceram o aparecimento das relações públicas (ANDRADE, 1993).

No Brasil, a atividade chegou no ano de 1914, com a criação do Departamento de Relações Públicas da The São Paulo Tramway Light and Power Go. (atual AES Eletropaulo), que foi o primeiro serviço regular de Relações Públicas a funcionar no país (GURGEL, 1985).

O departamento foi dirigido pelo engenheiro Eduardo Pinheiro Lobo, que ficou 19 anos no cargo e mais tarde foi considerado o patrono das Relações Públicas no Brasil. Esta empresa era um órgão estatal quando criou o Departamento de Relações Públicas, o que já nos permite afirmar que, no Brasil, a profissão teve dois momentos de significativa importância na prática comunicacional da esfera pública, pois conforme Andrade (1993), outro momento importante no desenvolvimento das atividades de relações públicas no âmbito da administração pública federal se deu pelo serviço de Informação e Divulgação do Ministério da Agricultura, que foi o primeiro informativo oficial, criado em 9 de dezembro de 1911, por meio do Decreto $n^{\circ} 9.195$.

Desde a chegada da profissão ao país, esta foi crescendo e conquistando seu espaço no cenário brasileiro. Alguns pontos foram importantes para a consolidação da atividade, como a criação do primeiro curso superior de Relações Públicas, em 1967, pela Escola de Comunicação e Artes da Universidade de São Paulo - USP e a regulamentação da profissão de Relações Públicas no Brasil, pela Lei $n^{\circ}$ 5.377, de 11 de dezembro de 1967.

A partir deste desenvolvimento, a profissão passou também a ser vista e utilizada estrategicamente no relacionamento entre o governo e seus públicos de interesse, passando assim a promover também a comunicação na esfera pública.

Desta forma, é possível perceber a forte ligação que há entre o exercício da profissão de Relações Públicas e a prática da comunicação na esfera governamental, visto que o governo também é uma organização que ne- cessita comunicar-se com seus públicos, tanto para informar ações de utilidade pública, como para estabelecer outras comunicações que colaborarão com o crescimento mútuo entre governo e governados.

Pretende-se, com esta pesquisa, responder alguns questionamentos referentes à área da comunicação no âmbito público, tais como: Quanto se publicou nesta área? Quais autores mais serviram de referência bibliográfica? Sobre quais expressões os artigos pesquisados mais discorreram? Estes questionamentos foram base norteadora para a execução desta pesquisa.

Neste sentido, o principal objetivo deste trabalho é analisar o campo de estudos da comunicação praticada na esfera pública por meio dos artigos publicados no Congresso Brasileiro de Ciências da Comunicação do Intercom e, consequentemente, realizar uma aferição dos autores e das publicações mais utilizados como referência para este campo de atuação.

Pautado no próprio objetivo, este artigo justifica-se pela importância de se conhecer quantitativamente dados relacionados à prática da comunicação no âmbito público e na relevância que este trabalho poderá ter, servindo de base para novos estudos na área.

É importante ressaltar ainda que a comunicação praticada na esfera pública envolve algumas expressões como comunicação governamental, comunicação pública, comunicação política, marketing político e propaganda política, portanto, tais expressões foram levadas em consideração na execução desta pesquisa e, na sequência, descreveremos a respeito de cada uma delas, diferenciando-as e aproximando-as em suas características.

Assim sendo, para a execução deste artigo lançou-se mão da pesquisa bibliográfica, utilizando-se do recurso bibliométrico que, de acordo com Andrade e Hoffmann (2007, p. 02) "tem servido à comunidade científica como ferramenta estatística para a gestão da informação e do conhecimento, além de constituirse em um instrumento de avaliação científica e tecnológica". Neste sentido, a bibliometria pode ser entendida como o estudo formal das citações, fundamental para averiguar as comunidades científicas.

Assim sendo, na sequência desta introdução segue uma breve descrição das expressões pesquisadas, uma revisão bibliográfica acerca 
do assunto abordado, alguns aspectos metodológicos utilizados, os resultados e análises obtidos e, por fim, algumas considerações finais que promovem uma breve discussão acerca dos resultados encontrados.

\section{Contextualizando as Expressões}

Quando referimo-nos ao mundo da política, a comunicação é um fator essencial, porém, as expressões e definições que permeiam esta área ainda carecem de clareza e objetividade. No Brasil, é frequente o uso ou a definição equivocada de expressões que dizem respeito ao exercício comunicacional na esfera pública.Logo, faz-se necessário diferenciar os conceitos das expressões utilizadas para delimitar esta pesquisa: comunicação governamental, comunicação política, comunicação pública, marketing político e propaganda política.

A comunicação governamental envolve toda a área de comunicação social e diversos canais de comunicação e pode ser entendida, conforme Torquato, como "uma rede formal e estruturada de comunicação, localizada no interior das organizações governamentais, com o objetivo de levar informações à opinião pública" (1985, p. 44).

Neste sentido a comunicação governamental é fortemente baseada na premissa da prestação de contas e na necessidade que o governo possui de estabelecer linhas de comunicação com a sociedade.

Já a comunicação política pode ocorrer, não apenas nos momentos de gestão pública, mas também nos momentos eleitorais (DORNELLES, 2002) e neste sentido Maicas (1992, p. 272) é objetivo ao afirmar que "por comunicação política devemos entender a relação entre a comunicação social e a política", sendo que esta não pode ser utilizada como um patrimônio dos governantes, mas sim envolver o cidadão.

Assim, "a comunicação política deve desenvolver, em toda sua profundidade, a relação entre o processo político, com suas distintas fases, ou seja, época de gestão e de período eleitoral" (MAICAS, 1992, p. 277).

Portanto, nota-se que a comunicação política procura manter seu discurso em todas as suas fases, para que possa trabalhar favoravel- mente a opinião pública e, consequentemente, embasar sua legitimidade, conquistando o apoio do público envolvido.

A expressão comunicação pública, por sua vez, foi muito discutida nos artigos pesquisados e, segundo estes, a essência de sua existência é a informação voltada para o cidadão.

Para Brandão (2006) pode-se entender comunicação pública como um espaço que propicia a negociação entre os interesses de todas as instâncias e de poder envolvidos em determinado processo, caracterizando assim, um procedimento de comunicação instaurado na esfera pública que envolve o Estado, o Governo e a sociedade.

Desse modo é visível a pluralidade deste conceito, uma vez que, para acontecer essa comunicação, é indispensável a atuação de várias instâncias que compõem o poder público, visto que a presença de apenas um desses atores sociais não promove a comunicação pública. Em suma, a comunicação pública "promove o fluxo de comunicação entre as necessidades da sociedade e aquelas disponíveis nas instituições públicas que são, por natureza, as portadoras do interesse geral" (BRANDÃO, 2006, p. 6).

Junto às expressões que permeiam a área pública, aparece com considerável frequência o marketing político que é utilizado estrategicamente para aproximar o cidadão eleitor aos políticos, partidos ou instituições governamentais.

De acordo com Gomes (2007) o marketing político é uma estratégia permanente que visa a constante aproximação entre o emissor/político e o receptor/cidadão. Garcia e Furquim (2004, p. 01) complementam esta informação ao afirmar que "o marketing político é um conjunto de estratégias de grande significação no cenário das campanhas eleitorais, pois permite ao candidato direcionar seus objetivos, propostas e ideais a um determinado nicho do eleitorado".

Bastante atrelada ao marketing político, há a propaganda política que, aliada às estratégias do marketing político, busca a criação e/ou formatação de determinada imagem. A propaganda política visa atingir a sociedade de massas e geralmente é marcada por slogans e símbolos.

A propaganda política visa associar imagens e agregar simbolismos aos candidatos para suprir as necessidades do público que necessita

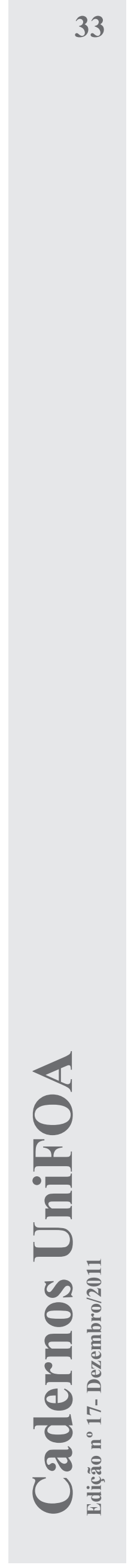


do sistema de ficção para poder confirmar suas próprias formas de satisfação (SILVA, 2006) e também necessita de algum tipo de identificação com o produto/candidato.

Contudo, nota-se que, embora muitas vezes utilizadas como sinônimos, as expressões aqui abordadas possuem suas peculiaridades e definições distintas e todas remetem-se à atividades que podem ser desenvolvidas por profissionais da comunicação, entre eles o relações-públicas.

Neste sentido, resgata-se que os acontecimentos que permeiam o início da atividade de Relações Públicas já registram a utilização estratégica da profissão no âmbito público e desta forma é importante abordar as Relações Públicas Governamentais que, segundo Andrade (1996, p. 105-106) refere-se a um "método de ação que, mediante diálogo planificado e permanente entre governantes e governados, procura determinar o interesse social". É possível, então, afirmar que, assim como em qualquer outra organização, também no governo o relações-públicas atua no relacionamento com os públicos por meio de estratégias comunicacionais, para desta forma manter um diálogo planificado e permanente.

Sabe-se que a presença de comunicadores sociais é fator indispensável para a execução eficiente da comunicação em qualquer que seja o segmento da organização e desta forma fica explícita a necessidade de relações-públicas, jornalistas e profissionais da propaganda atuando em prol da comunicação na esfera pública, uma vez que cada uma dessas habilitações possui suas capacidades peculiares e, atuando integradamente, formam o tripé da comunicação que pode executar a comunicação praticada na esfera pública.

\section{Metodologia}

Esta pesquisa possui caráter exploratório, pois busca compreender o que diz respeito ao campo de estudos referentes à comunicação praticada na esfera pública e envolve um levantamento bibliográfico acerca do referido assunto. De acordo com Richardson (2007, p. 66) os estudos de caráter exploratório são utilizados "quando não se tem informação sobre determinado tema e se deseja conhecer o fenômeno", neste sentido os estudos exploratórios "são orientados para a descoberta. Assim, são planos que não têm a intenção de testar hipóteses específicas de pesquisa" (HAIR JUNIOR et al, 2005, p. 84).

Para a realização desta pesquisa utilizou-se o método quantitativo, viabilizado por meio de uma pesquisa bibliográfica realizada nos artigos publicados no Congresso Brasileiro de Ciências da Comunicação do Intercom entre os anos de 1998 e 2008 e cuja análise é estatística.

Para Richardson (2007, p. 70) “o método quantitativo representa, em princípio, a intenção de garantir a precisão dos resultados, evitar distorções de análise e interpretação, possibilitando, consequentemente, uma margem de segurança quanto às inferências".

Dessa maneira, este método "deve ser precedido por uma reflexão sobre quais os atributos pelos quais os fenômenos estudados são dessemelhantes e podem ser ignorados em relação aos objetivos pretendidos" (EPSTEIN, 2006, p. 15). Sendo assim, ressalta-se que o objetivo desta pesquisa é a análise quantitativa pertinente aos artigos científicos, à estratégia, ao tipo de análise, ao construto e a linha de pesquisa utilizada pelos respectivos artigos publicados no Congresso Brasileiro de Ciências da Comunicação.

O método estatístico propõe-se a fornecer uma descrição quantitativa a respeito de determinado assunto, e segundo Marconi e Lakatos (2006) diz respeito a uma "redução de fenômenos sociológicos, políticos, econômicos etc. a termos quantitativos e a manipulação estatística, que permite comprovar as relações dos fenômenos entre si, e obter generalizações sobre sua natureza, ocorrência ou significado" (MARCONI; LAKATOS 2006, p. 108).

O tratamento dos dados foi realizado por meio de estatística descritiva e análise por correspondência, em que buscou-se investigar sobre a correspondência entre as linhas de pesquisa, os construtos, as abordagens e as estratégias utilizadas nos artigos pesquisados.

Foram utilizados como base referencial para a pesquisa, as expressões: comunicação governamental, comunicação política, comunicação pública, marketing político e propaganda política, que foram pesquisadas no título, resumo e palavras-chave dos artigos.

A escolha por estas expressões deu-se em função de serem estes os termos mais utilizados quando se refere à comunicação praticada 
na esfera pública, bem como ao fato de serem expressões que ainda carecem de mais objetividade em suas definições, principalmente, para facilitar o entendimento no mundo acadêmico.

No início desta pesquisa, também utilizou-se a expressão relações públicas governamentais para delimitação dos artigos, entretanto, nenhum artigo possui a referida expressão no título, resumo ou palavras-chave, por este motivo extinguiu-se o termo das palavras delimitadoras deste estudo.

É importante ressaltar que houve artigos que possuíam alguma abordagem referente à comunicação praticada na esfera pública, no entanto, por não estarem de acordo com os critérios de seleção, não fizeram parte da amostra selecionada.

Para a execução deste trabalho optou-se pelo evento Congresso Brasileiro de Ciências da Comunicação do Intercom - Sociedade Brasileira de Estudos Interdisciplinares da Comunicação, tendo em vista ser este um evento de respaldo e reconhecimento na área de comunicação no Brasil. A priori, foram selecionados todos os artigos publicados desde o ano de 1998 até o ano de 2008, totalizando 5.356 artigos. Deste total, por meio da base referencial acima descrita, segmentaram-se os artigos, chegando a uma amostra correspondente a 33 artigos selecionados. Estes artigos faziam parte de todos os Núcleos de Pesquisa disponíveis.

Para selecionar os artigos, executou-se uma pesquisa no site do evento e selecionouse todos os artigos disponíveis, desde o ano de 1998 até o ano de 2008. Após esta seleção, utilizou-se a ferramenta de pesquisa avançada do Windows para localizar os artigos que possuíam as especificações que delimitaram esta pesquisa, obtendo como resultado 33 artigos .

Esses mesmos artigos foram fichados e respectivamente utilizados como base teórica, visto que considerara-se importante apresentar uma breve contextualização sobre as expressões que delimitam este trabalho.

Tabela 1 - Categorias Pesquisadas

\begin{tabular}{|c|c|c|c|c|c|}
\hline \multicolumn{2}{|c|}{ Categorias Pesquisadas* } \\
\hline Expressões & Construtos & Estratégia & Abordagem & $\begin{array}{c}\text { Instituições de Ensino que } \\
\text { apareceram > 3 vezes }\end{array}$ & $\begin{array}{c}\text { Estados que } \\
\text { apareceram } \\
>3 \\
\text { vezes }\end{array}$ \\
\hline Comunicação & $\begin{array}{c}\text { Divulgação } \\
\text { Governamental }\end{array}$ & Documental & Qualitativa & $\begin{array}{c}\text { Pontifícia Universidade } \\
\text { Católica do Paraná }\end{array}$ & Paraná \\
\hline Comunicação Política & Legitimidade & Estudo & Quantitativa & Pontifícia Universidade Católica & Rio Grande \\
do Rio Grande do Sul & do Sul \\
\hline Comunicação Pública & $\begin{array}{c}\text { Exercício da } \\
\text { Cidadania }\end{array}$ & Questionário & & Universidade de São Paulo & São Paulo \\
\hline Propaganda Política & Formatação & & & Universidade Metodista & de São Paulo \\
\hline
\end{tabular}

Fonte: Elaborado pelos autores. * Informações apresentadas por ordem alfabética

Foram pesquisadas as categorias apresentadas na Tabela 1 que assemelham-se àquelas pesquisadas por Andrade e Hoffmann (2007) e levam em consideração o interesse pelas referidas informações coletadas.

Para cada expressão norteadora deste trabalho, chegou-se a um construto. Os construtos foram definidos com base na leitura dos 33 artigos selecionados e desta forma foi possível observar que todas as expressões, embora com suas peculiaridades, possuem certa relação e que se pode traçar um parâmetro de hegemonia das expressões e dos respectivos construtos que permeiam a área da comunicação praticada na esfera pública. $\mathrm{O}$ construto divulgação de ações foi relacionado à comunicação governamental devido ao fato de o governo possuir, dentre outras funções comunicacionais, a premissa básica de divulgar aquilo que faz para a sociedade e assim manter uma linha de comunicação e informação com os cidadãos, criando sua identidade e se fazendo presente para não cair no esquecimento. 
Já quando refere-se à comunicação política, o construto é a legitimidade, uma vez que é por meio da comunicação política que partidos, candidatos, políticos e instituições governamentais pleiteiam credibilidade junto a todas as instâncias da sociedade para que, dessa forma, possam legitimar-se junto aos seus públicos de interesse.

Em relação a comunicação pública, os estudos presentes nos artigos apontam para uma intrínseca relação com o exercício da cidadania visto que envolve um debate entre Estado, governo e sociedade em busca de uma tomada de decisões em prol da vida pública do país, assim sendo, este tipo de comunicação promove um incentivo à cidadania e só ocorre com a presença desta, bem como da democracia.

O marketing político e a propaganda política são as expressões que possuem seus construtos mais diretamente ligados. Com base nos artigos, observou-se que frequentemente os estudos relacionados a ambas as expressões caminham direcionados a uma manipulação ou criação de determinada imagem pública.

Assim sendo, o marketing político é responsável pelas estratégias que irão formatar esta imagem, enquanto a propaganda política é aquela que possui a função de utilizar ferramentas, como símbolos e slogans, para complementar esta formatação de imagem.

Ainda por meio das categorias pesquisadas, observou-se que as principais estratégias de pesquisa utilizadas são documental, estudo e questionário, com abordagem tanto qualitativa como quantitativa, porém, com uma predominância da utilização de abordagem qualitativa.Como critério para selecionar as instituições de ensino superior e os estados, utilizou-se aqueles que apareceram em número igual ou superior a 3 vezes, e para os auto- res citados em referências, aqueles que apareceram em número igual ou superior a 6 vezes. Desta forma, notou-se que as instituições de ensino superior que mais publicaram estão nos estados do Paraná, Rio Grande do Sul e São Paulo, sendo elas PUCPR, PUCRS, USP e Metodista de São Paulo.

\section{Resultados}

Conforme os critérios metodológicos informados, foram selecionados 33 artigos publicados no Congresso Brasileiro de Ciências da Comunicação do Intercom, entre os anos de 1998 a 2008. Optou-se para este trabalho, usar artigos publicados no Intercom, por questões de acessibilidade e por considerar adequada sua utilização.

No congresso pesquisado, estavam disponíveis 5.356 artigos no qual 33 correspondiam à metodologia utilizada para sua seleção. Essa amostra representa um percentual de confiabilidade de 92,07\% com erro amostral de 7.93\% (BARBETA, 2007). A Tabela 2 apresenta o total de artigos pesquisados e as áreas temáticas, utilizados como critérios para seleção dos artigos. Fica claro, na tabela, que houve um aumento expressivo de publicações da base referencial pesquisada, uma vez que 54\% delas foram publicadas entre 2006 e 2008 . Outra observação a se considerar é que no ano de 2001 não houve nenhuma publicação. Dos artigos pesquisados, quase $34 \%$ versa sobre marketing político. O termo é muito popular e é, muitas vezes, aplicado erroneamente como sinônimo de outras expressões aqui abordadas, fato que pode justificar sua maior incidência dentre as demais expressões pesquisadas. 
Tabela 2 - Número de artigos, ano de publicação e áreas selecionadas

\begin{tabular}{|c|c|c|c|c|c|c|c|}
\hline Ano & $\begin{array}{l}\text { Comunicação } \\
\text { Governamental }\end{array}$ & $\begin{array}{c}\text { Comunicação } \\
\text { Política }\end{array}$ & $\begin{array}{l}\text { Comunicação } \\
\text { Pública }\end{array}$ & $\begin{array}{c}\text { Marketing } \\
\text { Político }\end{array}$ & $\begin{array}{c}\text { Propaganda } \\
\text { Política }\end{array}$ & Total & $\%$ \\
\hline 1998 & & 1 & & 1 & 1 & 3 & 9,09 \\
\hline 1999 & & & 2 & 2 & & 2 & 6,06 \\
\hline 2000 & & 1 & & & & 1 & 3,03 \\
\hline 2001 & -------- & -------- & --------- & -------- & -------- & ------ & ------ \\
\hline 2002 & & 2 & & 1 & & 3 & 9,09 \\
\hline 2003 & & & 1 & 1 & & 2 & 6,06 \\
\hline 2004 & & & & & 3 & 3 & 9,09 \\
\hline 2005 & & 1 & & & & 1 & 3,03 \\
\hline 2006 & 1 & 1 & 3 & 2 & 1 & 8 & 24,24 \\
\hline 2007 & & & 1 & 3 & & 4 & 12,12 \\
\hline 2008 & 2 & & & 2 & 2 & 6 & 18,18 \\
\hline Total & 3 & 6 & 7 & 12 & 7 & 33 & 100 \\
\hline
\end{tabular}

Fonte: Dados da pesquisa. Elaborado pelos autores.

Dentre os anos dos artigos publicados, o ano de 2006, além de apresentar o maior número de artigos, apresentou também uma frequência nas publicações, todos os temas foram contemplados, com destaque para a comunicação pública, que neste ano apresentou uma incidência maior em comparação às demais expressões.

A expressão marketing político foi sobre o que os artigos mais discorreram a respeito, totalizando 34\%. Seguido do marketing político, estão as expressões Propaganda Política e Comunicação Pública com $20 \%$ de incidência cada uma, a expressão Comunicação Política apareceu em $17 \%$ dos artigos e por fim a Comunicação Governamental ficou com um índice de incidência nos artigos de 9\%. Na Figura 1, apresenta-se os núcleos de pesquisa e os respectivos percentuais encontrados. Ao realizar uma comparação entre os resultados desses núcleos e as linhas de pesquisa que nortearam este trabalho, pode-se inferir que há uma relação intrínseca entre eles, haja vista que os núcleos "Publicidade, Propaganda e Marketing" e "Relações Públicas e Comunicação Organizacional" concentram 57,57\% dos artigos publicados, enquanto que as linhas de pesquisa Marketing Político, Comunicação Pública e Propaganda Política representam 74\% destes artigos. Neste sentido, observa-se uma significativa representatividade dessas linhas de pesquisa, bem como dos referidos núcleos, e pode-se entender ainda que uma informação ratifica a outra, apontando para uma vertente que escreve sobre a comunicação praticada na esfera pública e submete seus artigos aos núcleos de "Publicidade, Propaganda e Marketing” e "Relações Públicas e Comunicação Organizacional”.
Figura 1 - Distribuição percentual dos núcleos de pesquisa.

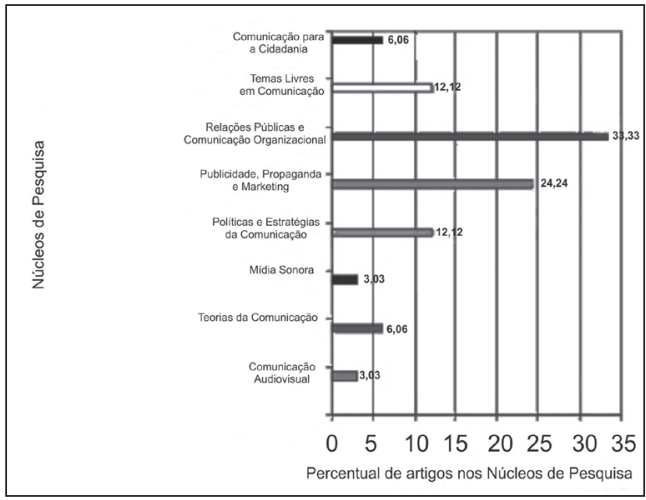

Fonte: Elaborado pelos autores.

Ainda com base na Figura 1, nota-se que não há nenhum núcleo de pesquisa voltado especificamente para a comunicação na esfera pública, o que pode caracterizar-se como uma falta de incentivo para se escrever sobre o assunto, uma vez que, num universo de 5.356 artigos, encontrou-se apenas 33 que, de fato, possuíam um direcionamento bem específico para a comunicação na esfera pública.

Devido ao fato de os núcleos de pesquisa "Publicidade,PropagandaeMarketing"e "Relações Públicas e Comunicação Organizacional" possuírem o maior número de artigos submetidos, pode-se entender que a maioria dos artigos sob linha Marketing Político e Propaganda Política foram submetidos ao núcleo de pesquisa "Publicidade, Propaganda e Marketing", enquanto que a maioria dos artigos sob linha Comunicação Governamental, Comunicação Pública e Comunicação Política foram submetidos ao núcleo "Relações Públicas e Comunicação Organizacional". 
Figura 2 - Mapa perceptual - Linhas, construtos, estratégias e abordagens.

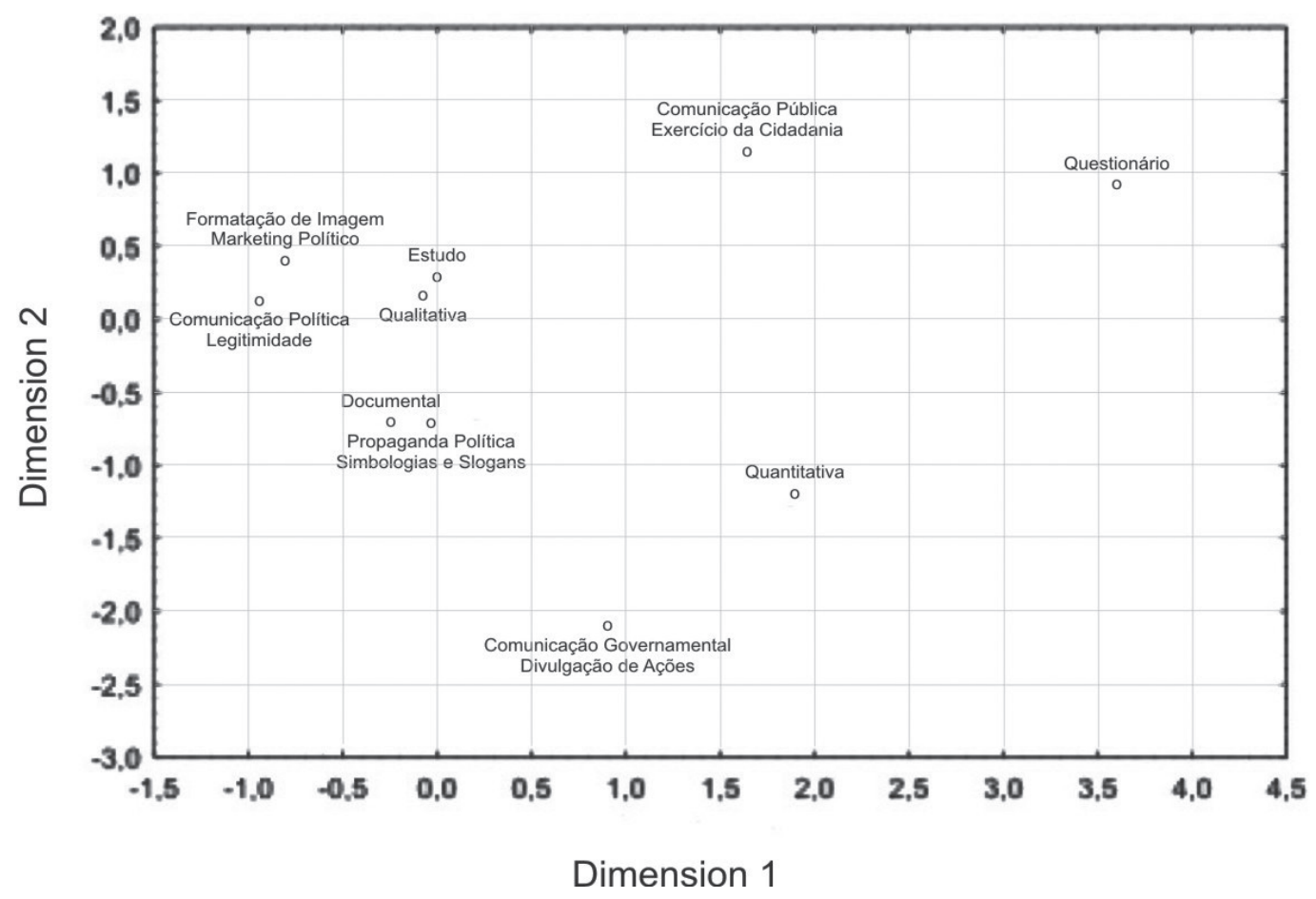

Fonte: Elaborado pelos autores.

De acordo com a Figura 2, pode-se evidenciar que os construtos Formatação de Imagem e Legitimidade possuem correspondência com a estratégia Estudo e a abordagem Qualitativa. Do mesmo modo observa-se que o construto Simbologias e Slogans possui correspondência com a estratégia Documental.

Ainda com base na Figura 2, nota-se que as linhas Comunicação Governamental e Comunicação Pública, a abordagem quantitativa e a estratégia Questionário não são comumente utilizadas para este tipo de pesquisa.

A linha Comunicação Pública, apesar de possuir uma representatividade de $20 \%$ dos artigos publicados, ficou separada das demais linhas, o que pode apontar que, apesar de pesquisas quantitativas não serem frequentemente utilizadas, observou-se neste caso, que um artigo referente à Comunicação Pública possuía abordagem quantitativa, visto que o autor do referido artigo objetivava quantificar, por meio de um questionário estruturado aplicado em empresas públicas, informações relativas à como os profissionais percebem o trabalho que desempenham.

Percebe-se ainda que, no que se refere ao estudo da comunicação é incomum encontrar análises com viés quantitativo, bem como a utilização de questionários, visto que estas estratégias são utilizadas no intuito de quanti- ficar informações, enquanto que no campo dos estudos comunicacionais, geralmente, o intuito é de relatar, descrever e apresentar fatos e informações, utilizando-se de abordagens qualitativas.

Já na Tabela 3, apresenta-se a relação dos autores que foram citados em número igual ou maior que 6 vezes e a respectiva quantidade de citação que cada um teve.

Tabela 3 - Autores e quantidade de citações em referências bibliográficas

\begin{tabular}{|c|c|}
\hline Autor & Número de Citações \\
\hline ANDRADE, C. T. S. & 6 \\
\hline GOMES, N. D. & 6 \\
\hline PERELMAN, C. & 6 \\
\hline WOLTON, D. & 6 \\
\hline RUBIM, A. A. & 7 \\
\hline WEBER, M. H. & 7 \\
\hline TORQUATO, F. G. & 8 \\
\hline HABERMAS, J. & 11 \\
\hline MATOS, H. & 12 \\
\hline
\end{tabular}

Fonte: Dados da pesquisa. Elaborado pelos autores. 
É importante ressaltar que os autores acima citados foram encontrados nos artigos que fizeram parte da amostra desta pesquisa e foram selecionados porque possuíam incidência maior ou igual a 6. Dessa forma todos os demais autores que não chegaram a alcançar incidência igual a 6 não foram selecionados e, portanto, não aparecem na Tabela 3.

A partir da seleção desses autores, buscou-se investigar, por meio do banco de da- dos disponível no site do Conselho Nacional de Desenvolvimento Científico e Tecnológico (CNPq), a formação acadêmica. Optou-se por esses autores tendo em vista que num universo de 33 autores, esses 9 representam $43,12 \%$ das citações nas referências bibliográficas dos artigos. Assim, chegou-se ao resultado que apresenta-se na Tabela 4.

Tabela 4 - Relação dos autores com incidência igual ou superior a 6 vezes nas referências bibliográficas dos artigos e sua respectiva formação acadêmica

\begin{tabular}{|c|c|}
\hline Autor & Formação Acadêmica \\
\hline Cândido Teobaldo de Souza Andrade* & $\begin{array}{l}\text { Graduado em Educação Física e Direito / } \\
\text { Doutor em Comunicação (Relações Públicas) }\end{array}$ \\
\hline Neusa Demartini Gomes & $\begin{array}{l}\text { Graduada em Jornalismo / Doutora } \\
\text { em Sociologia da Comunicação Política }\end{array}$ \\
\hline Chaim Perelman* & Filósofo da área do Direito \\
\hline Dominique Wolton & Cientista político graduado em Sociologia \\
\hline Antonio Albino Rubim & $\begin{array}{l}\text { Graduado em Comunicação } \\
\text { / Doutor em Sociologia }\end{array}$ \\
\hline Francisco Gaudêncio Torquato do Rego & Graduado em Comunicação Social \\
\hline Jürgen Habermas & $\begin{array}{l}\text { Graduado em Filosofia, História } \\
\text { e Literatura / Doutor em Filosofia }\end{array}$ \\
\hline Maria Helena Weber & $\begin{array}{l}\text { Graduada em Comunicação Social } \\
\text { / Doutora em Comunicação }\end{array}$ \\
\hline Heloiza Matos & $\begin{array}{l}\text { Graduada em Jornalismo / Pós } \\
\text { Doutora em Comunicação Política }\end{array}$ \\
\hline
\end{tabular}

* Em Memória

Fonte: Dados da Pesquisa. Elaborado pelos autores.

De acordo com a Tabela 4, observa-se que, dentre os autores mais utilizados como referência bibliográfica, há um número expressivo de autores de outras áreas do conhecimento que direcionaram suas carreiras para a comunicação e, atualmente, servem de referência para esta área, pois autores que não possuíam graduação em cursos vinculados à comunicação acabaram por direcionar seus estudos posteriores, como especializações, para a mesma. Tal informação nos remete à constatação de que a temática que aborda a comunicação na esfera pública não costuma preocupar ou interessar os profissionais de comunicação formados na área, o que acaba por abrir espaço para que profissionais de outras áreas, nem sempre afins, atuem dentro da comunicação, como pode-se ratificar observando a Tabela 4.

\section{Considerações Finais}

Com base nas pesquisas realizadas, concluise que os resultados apresentados apontam que há pouco interesse sobre os temas publicados haja vista o grande número de artigos enviados com relação à amostra encontrada, outro fator que pode justificar este fato consiste na inexistência de um núcleo de pesquisa específico para a área da comunicação praticada na esfera pública. Observou-se que, a partir do ano de 2006, houve um incremento na publicação a respeito dos temas pesquisados, destacando o mesmo ano que teve publicação em todas as linhas de pesquisa, o que pode caracterizar-se como um sinal positivo para a academia, visto que nos últimos anos houve uma progressão no número de publicações. 
Ao analisar os autores mais citados e suas respectivas formações universitárias, observa-se que ao longo do tempo a área da comunicação teve considerável progressão em âmbito acadêmico. Cada vez mais as pessoas que atuam nestas áreas têm buscado formarse e especializar-se na mesma, o que também pode sinalizar como uma contribuição para o incremento de publicações nesta área, como foi possível observar a partir do ano de 2006.

Este fato também sinaliza para a profissionalização do mercado da comunicação, tendo em vista a importância que a comunicação tem para a sociedade, neste sentido observase que tudo se dá por meio da comunicação, não obstante, quando refere-se à comunicação praticada por organizações faz-se necessário a presença de profissionais habilitados para bem desempenhá-la.

No que tange as linhas de pesquisa mais utilizadas, chegou-se ao resultado de que num universo de 33 artigos, 34\% deles discorrem sobre marketing político. Este resultado pode apontar para uma discussão antiga sobre marketing x comunicação, como também pode abrir discussões a respeito da integração dos profissionais destas áreas em prol de um mesmo objetivo, oportunizando assim a elaboração de novos trabalhos voltados para este tipo de questionamento. 
1. ANDRADE,C.T.S.Dicionárioprofissional de Relações Públicas e Comunicação e glossário de termos anglo-americanos. 2. ed. São Paulo: Summus, 1996.

2. _ Para entender Relações Públicas. São Paulo: Loyola, 1993

3. ANDRADE, M. A. R.; HOFFMANN, V. E. Redes do século XXI: uma pesquisa bibliométrica em periódicos nacionais e internacionais no período de 2000 a 2005. In: VII SEMINÁRIO DE INICIAÇÃO CIENTÍFICA, 2007, Itajaí. Livro de Resumos, Itajaí, 2007.

4. BARBETA, P. A. Estatística aplicada às ciências sociais. 7 ed. Florianópolis: UFSC, 2007.

5. BRANDÃO, E. P. Usos e Significados do Conceito Comunicação Pública. In: XXIX CONGRESSO BRASILEIRO EM CIÊNCIAS DA COMUNICAÇÃO, 2006, Brasília. Anais Eletrônicos, Brasília, 2006. CD-ROM.

6. DORNELLES,S.M.G.OEspaçodasRelações Públicas no Cenário da ComunicaçãoPública. In: XXV CONGRESSO BRASILEIRO DE CIÊNCIAS DA COMUNICAÇÃO, 2002, Salvador. Anais Eletrônicos, Salvador, 2002. CD-ROM.

7. EPSTEIN, I. Ciência, poder e comunicação.In: DUARTE, J.; BARROS, A. Métodos e Técnicas de Pesquisa em Comunicação. 2 ed. São Paulo: Atlas, 2006. p. 15-31.

8. GARCIA, P. M.; FURQUIM, V. M. Marketing Político: as táticas políticocomunicacionais de Vargas, Jânio e Collor. In: XXV CONGRESSO BRASILEIRO EM CIÊNCIAS DA COMUNICAÇÃO, 2002, Salvador. Anais Eletrônicos, Salvador, 2002. CD-ROM.
9. GOMES, N.D. Os instrumentos do marketing político e eleitoral e a persuasão como elemento comum entre eles para a formação da opinião pública. In: XXX CONGRESSO BRASILEIRO EM CIÊNCIAS DA COMUNICAÇÃO, 2007, Santos. Anais Eletrônicos, Santos, 2007. CD-ROM.

10. GURGEL, J. B. S. Cronologia da Evolução Histórica das Relações Públicas. 3 ed. Brasília: Linha Gráfica e Editora, 1985.

11. HAIRJUNIOR, J.F.etal. Fundamentos de Métodos de Pesquisa em Administração. Porto Alegre: Bookman, 2005

12. MAICAS, M. P. I. Introducion a la comunicación social. Barcelona: ESRPPPU, 1992.

13. MARCONI, M. A.; LAKATOS, E. M. Metodologia do trabalho científico. 5.ed. São Paulo: Atlas, 2001.

14. RICHARDSON, R. J. Pesquisa Social: métodos e técnicas. 3 ed. São Paulo: Atlas, 2007.

15. SILVA,D.P. Odesencantamento no mundo da política. A propaganda, o marketing e o consumo de um candidato que virou presidente. In: XXIX CONGRESSO BRASILEIRO DE CIÊNCIAS DA COMUNICAÇÃO, 2006, Brasília. Anais Eletrônicos, Brasília, 2006. CD-ROM.

16. STUMPF, I. R. C. Pesquisa Bibliográfica. In: DUARTE, J.; BARROS, A. Métodos e Técnicas de Pesquisa em Comunicação. 2 ed. São Paulo: Atlas, 2006. p. 52-61.

17. TORQUATO, F. G. Marketing Político e Governamental: um roteiro para campanhas políticas e estratégias de comunicação. São Paulo: Summus, 1985.

\footnotetext{
Endereço para Correspondência:

Francine Lucatelli

fran_lucatelli@univali.br

Rua Uruguai, 621, Bloco B - Apto. 307

Fazenda, Itajaí - SC

CEP: 88302-203
} 